\title{
Identifying the combined effect of shared autonomous vehicles and congestion pricing on regional job accessibility
}

\author{
Shaopeng Zhong \\ Dalian University of Technology \\ szhong@dlut.edu.cn

\section{Xufeng Li} \\ Dalian University of Technology \\ 952241910@qq.com
}

\section{Yu Jiang (corresponding author) Technical University of Denmark yujiang@dtu.dk}

\author{
Rong Cheng \\ Dalian University of Technology \\ 804680460@qq.com
}

\author{
Zhong Wang (corresponding author) \\ Dalian University of Technology \\ zwang@dlut.edu.cn
}

\begin{abstract}
Most of the existing research on shared autonomous vehicles (SAVs) and road congestion pricing have studied the short-term impact on traffic flow. These types of studies focused on the influences on mobility and ignored the long-term impacts on regional job accessibility. Given this, from the perspective of land use and transportation integration, this study explored the long-term effects of SAVs and cordon-based congestion pricing on regional land use, transportation, and job accessibility. The contributions of this study have been summarized by the following three purposes. First, to the best of the authors' knowledge, this study was the first attempt to identify the long-term impact of the combination of these two technologies on regional job accessibility. Second, compared to the previous research methodology, this study adopted the land use and transportation integrated model (TRANUS model) and scenario planning to ensure the comprehensiveness and validity of the results. Third, this study analyzed the spatial heterogeneity of the impact of the combination of the two technologies on regional job accessibility in different areas with different built-environment attributes. To realize this purpose, this study quantitatively classified traffic analysis zones (TAZs) using data mining technology, i.e., factor analysis and clustering analysis. Results showed that the introduction of SAVs will contribute to job and population development in the charging zone and reduce the negative effect of road congestion pricing. From the perspective of reducing the average travel time between TAZs, the best strategy will be to implement SAVs alone, followed by integrated use of SAVs and road congestion pricing, while the worst strategy will be to implement the cordon-based congestion pricing policy alone. By comparison, from the perspective of improving regional job accessibility, the effect of introducing SAVs was better than that of road congestion pricing, while the combination of these two technologies was not superior to implementing SAVs alone.
\end{abstract}

Keywords: Shared autonomous vehicles, road congestion pricing, accessibility, land use and transportation integrated model, data mining

Copyright 2020 Shaopeng Zhong, Rong Cheng, Xufeng Li, Zhong Wang \& Yu Jiang http://dx.doi.org/10.5198/jtlu.2020.1692

ISSN: 1938-7849 | Licensed under the Creative Commons Attribution - Noncommercial License 4.0

The Journal of Transport and Land Use is the official journal of the World Society for Transport and Land Use (WSTLUR) and is published and sponsored by the University of Minnesota Center for Transportation Studies.
Received: November 27, 2019

Received in revised form: March 8, 2020

Accepted: April 15, 2020

Available online: October 29,2020

\section{Article history:}




\section{Introduction}

Shared Autonomous Vehicles (SAVs) will be integrated into people's daily lives in the next ten to twenty years (Wadud, MacKenzie, \& Leiby, 2016; Milakis, Snelder, van Arem, van Wee, \& de Almeida Correia, 2017a; Litman, 2018; Narayanan, Chaniotakis, \& Antoniou, 2020). Although SAVs technology has been developed rapidly, there are still doubts in academia and for policy-makers about whether and how SAVs contribute to the sustainable development of society. On the one hand, existing research found that SAVs have potentially positive effects on improving traffic efficiency (Fagnant $\&$ Kockelman, 2014; Tian et al., 2015; Li et al., 2016b), road capacity (Talebpour \& Mahmassani, 2016), and road safety (Gong, Shen, \& Du, 2016; Li, Wang, Wang, Liu, \& Xiang, 2016a). On the other hand, scholars have pointed out that $S A V$ s could reduce travelers' marginal travel costs and encourage travelers to make longer and more frequent travel (Heinrichs, 2016). Meanwhile, SAVs will also encourage residents who are unable to drive independently, e.g., the old, children, and disabled people to travel by cars, which will generate more induced travel demand, resulting in longer total vehicle miles traveled (Milakis, van Arem, \& van Wee, 2017b). Bischoff and Maciejewski (2016) confirmed this point of view and found that the total vehicle miles traveled in Berlin, Germany increased by $13 \%$ when SAVs are introduced. The increased total vehicle miles traveled will lead to decentralized and low-density urban growth, which results in traffic congestion and impedes sustainable urban development. This is similar to the impact of motorization (large-scale use of private cars) on urban sprawl in the United States. Urban sprawl is a phenomenon of out-of-control expansion and sprawl in the urbanized areas, which makes the activities originally concentrated in the central area spread to the periphery of the city. The urban form presents the characteristics of decentralization, low density, single regional function, and car-dependent travel.

The large-scale implementation of SAVs will inevitably have impacts on various aspects. Clarifying these potential impacts can provide a basis for policy-makers to formulate development strategies for SAVs more rationally. According to Table 1, the ripple effects of urban land use and transportation systems caused by SAVs can be divided into three levels, i.e., transportation system, spatial locations of land use, and society (Milakis et al., 2017b). There are extremely complex interactions and constraints between urban land use and transportation systems. This relationship constitutes a "spiral" interaction among land use, accessibility, travel costs, and travel demand (Yang, Lu, Cherry, Liu, \& Li, 2017; Zhong \& Bushell, 2017b; Sun, Zhang, \& Shen, 2018). Specifically, the implementation of SAVs will first affect residents' travel behaviors and road traffic flow, which is known as the first-order effects. Due to the improvement of ride comfort, the traveler's value of time is reduced, which encourages residents to live far away from their workplace and accept longer commutes; for companies, they will choose the urban peripheral area with a lower cost to set up factories. This is the second-order effects. In terms of extensive social impacts (the third-order effects), changes in residents' travel behaviors and spatial locations will influence the long-term urban accessibility, air quality, energy consumption, and social equity, and re-influence residents' travel behaviors and traffic flow (Fan \& Khattak, 2008; Sun \& Ding, 2019). According to the above mechanism, the various effects of SAVs will interact with each other circularly until the urban system reaches an equilibrium state. 
Table 1. Ripple effects of SAVs

\begin{tabular}{|c|c|c|}
\hline Classification of the effects of SAVs & $\begin{array}{l}\text { The time required to exert } \\
\text { influence }\end{array}$ & Description of the effects \\
\hline $\begin{array}{l}\text { First-order effects (effects on transportation } \\
\text { system) }\end{array}$ & Short-term & $\begin{array}{l}\text { Change travelers' behavior, e.g., travel } \\
\text { frequency, travel time, travel mode, } \\
\text { and travel route; influence road capac- } \\
\text { ity and traffic flow. }\end{array}$ \\
\hline $\begin{array}{l}\text { Second-order effects (effects on the spatial loca- } \\
\text { tions of land use) }\end{array}$ & $\downarrow$ & $\begin{array}{l}\text { Influence the locations of residents' } \\
\text { activities, e.g., residences, work- } \\
\text { places, schools, shopping arcades, and } \\
\text { entertainment places; influence the } \\
\text { locations of the companies. }\end{array}$ \\
\hline Third-order effects (extensive social effects) & Long-term & $\begin{array}{l}\text { Extensive social effects: accessibility, } \\
\text { urban sprawl, energy consumption, air } \\
\text { quality, and social equity. }\end{array}$ \\
\hline
\end{tabular}

Although the various effects of SAVs interact with each other, most of the existing literature studied the short-term effects of SAVs on residents' travel behaviors and traffic flow (the first-order effects) (Fagnant \& Kockelman, 2014; Gong et al., 2016; Talebpour \& Mahmassani, 2016; Chen, He, Yin, \& Du, 2017), which focused on the effects of SAVs on mobility. The long-term effects (the second-order and third-order effects) of SAVs have not been explored in-depth (Heinrichs, 2016). Due to the ignorance of exploring the interactive feedback relationship between urban land use and transportation, it is difficult to analyze the long-term effects of SAVs on urban sprawl and accessibility (Childress, Nichols, Charlton, \& Coe, 2015; Milakis et al., 2017b). Mobility refers to the ease of movement, while accessibility refers to the ease of arriving at activities. The former reduces the travel cost per mile of travelers, while the latter reduces the cost of travelers arriving at each activity (Levine \& Garb, 2002; Zhong \& Bushell, 2017a). It has been proved that the improvement of mobility brought by cars does not necessarily improve the accessibility (Ewing, Schmid, Killingsworth, Zlot, \& Raudenbush, 2008). This is confirmed by the synchronous process of motorization and urban sprawl in the United States. The increased mobility brought by cars has contributed to the low-density development of American cities, resulting in the separation of different activities in space and the further commuting distance of residents. Eventually, accessibility declines significantly.

As a traffic demand management measure to alleviate traffic congestion, road congestion pricing has been successfully applied in many major cities around the world, such as Singapore, London, Stockholm, Milan, etc. (Zhong, Xiao, Bushell, \& Sun, 2017). The purpose of road congestion pricing is to adjust the traffic flow on the crowded roads during peak hours, so as to reduce road traffic congestion (Pigou, 1920; Yang \& Huang, 1998; Zhang \& Yang, 2004; de Palma \& Lindsey, 2011; Meng, Liu, \& Wang, 2012; Wei \& Sun, 2018). The introduction of SAVs has brought new challenges to the studies of traditional road congestion pricing. First, SAVs will reduce the value of time of travelers who use SAVs. From the perspective of marginal cost, this will damage the interest of the traveler using traditional vehicles, because his or her value of time does not change (Simoni, Kockelman, Gurumurthy, \& Bischoff, 2019). Second, SAVs and road congestion pricing will have different effects on short-term travel behaviors (e.g., travel route, departure time, travel mode, and travel frequency) of different types of travelers. Finally, and more importantly, SAVs and road congestion pricing also have long-term effects on the spatial locations of residence, business, and industry (Zhong \& Bushell, 2017b). In summary, the 
problem of road congestion pricing becomes more complicated after the introduction of SAVs.

The era of SAVs is coming, following with a series of problems related to mobility and accessibility. Will SAVs improve accessibility? Or is it just to improve mobility and contribute to the urban sprawl? Furthermore, to promote job accessibility, which technology is more effective, by introducing SAVs alone or implementing road congestion pricing alone? Will the combination of SAVs and road congestion pricing lead to better results?

To answer the above questions, from the perspective of land use and transportation integration, this study examined the long-term effects of SAVs and road congestion pricing on urban land use, transportation, and job accessibility. The contributions of this study are summarized in the following three aspects. First, to the best of the authors' knowledge, this study is the first study to explore the long-term impact of the integration of SAVs and road congestion pricing on regional job accessibility. Second, different from the methods used in the existing studies, this study applied the land use and transportation integrated model as well as scenario planning to explore the interactive feedback relationship between land use and transportation to ensure the comprehensiveness and effectiveness of the results. Third, this study used data mining technology (factor analysis and clustering analysis) to classify the traffic analysis zones (TAZs) quantitatively, so that we can analyze the spatial heterogeneity of the combined effects of the two technologies on job accessibility in different regions with different built environment attributes.

The rest of the paper is organized as follows. Section 2 reviews the existing literature. Section 3 and section 4 introduce the study area and research methodology, respectively. Section 5 analyzes the long-term effects of SAVs and road congestion pricing on land use, transportation, and regional job accessibility. Finally, section 6 concludes this study.

\section{$2 \quad$ Literature review}

As mentioned before, the existing research focused on the short-term effects of SAVs on residents' travel behaviors and traffic flow, only a few studies focused on the long-term effects of SAVs on regional accessibility. Unfortunately, there seems to be no study analyzing the long-term effects of the integration of SAVs and road congestion pricing on regional job accessibility. Given this, this section reviews the existing literature from two aspects: the long-term effects of SAVs on regional job accessibility and the research of road congestion pricing in the environment of SAVs.

\subsection{The long-term effect of SAVs on regional accessibility}

Due to the complex interactive relationship between land use and transportation, studies on the longterm effect of SAVs on regional accessibility are rare (see Table 2). From Table 2, it can be seen that the existing research tends to find out the qualitative relationship between SAVs and regional accessibility using simplified methods such as expert-based experiment (Milakis, Kroesen, \& van Wee, 2018), scenario planning (Papa \& Ferreira, 2018) or a combination of the two methods (Cohen \& Cavoli, 2019). The main conclusions of the existing studies are that: the accessibility variation caused by SAVs are highly uncertain and the travel time and cost savings brought by SAVs may be offset by the induced traffic demand (Milakis et al., 2018); considering different government decisions will lead to different effects of SAVs on accessibility, the improperly use of SAVs will increase residents' dependence on cars and total vehicle miles traveled, and further lead to traffic congestion (Papa \& Ferreira, 2018; Cohen \& Cavoli, 2019).

Although the above studies have found the negative effects of SAVs on accessibility, due to the lack 
of quantitative analysis, it is difficult for policy-makers to accurately identify sensitive areas that are negatively affected by SAVs and take corresponding countermeasures. To this end, some scholars have tried to use the macroscopic transportation demand model to quantitatively analyze the long-term effect of SAVs on regional accessibility. For example, using an independent macroscopic transportation demand model, Meyer, Becker, Bösch, and Axhausen (2017) found that although SAVs can improve the overall accessibility in Switzerland, especially in the suburbs, it will also cause a decline in accessibility in about $15 \%$ of the areas with a maximum decline rate of $29 \%$.

It is worth noting that although the long-term effect of $S A V$ s on regional accessibility can be quantitatively analyzed using the macroscopic transportation demand model, there are still great limitations of the existing research. The existing models and methods are not comprehensive due to the lack of analysis of the interactive feedback relationship between land use and transportation (Acheampong $\&$ Silva, 2015). More importantly, although the existing studies have found the negative effects of SAVs on accessibility, the spatial heterogeneity of the effects of SAVs on the accessibility in regions with different built environment attributes have not been studied.

Table 2. Main research results of the effect of SAVs on regional accessibility

\begin{tabular}{|c|c|c|c|}
\hline $\begin{array}{l}\text { The potential } \\
\text { effect of SAVs }\end{array}$ & $\begin{array}{l}\text { Authors and publi- } \\
\text { cation year }\end{array}$ & Model and method & Main conclusion \\
\hline \multirow{4}{*}{$\begin{array}{c}\text { Regional } \\
\text { accessibility }\end{array}$} & Meyer et al. (2017) & $\begin{array}{l}\text { The macroscopic } \\
\text { transportation } \\
\text { demand model }\end{array}$ & $\begin{array}{l}\text { SAVs will increase national accessibility in Switzerland, } \\
\text { especially in the suburbs, but it will also cause a decline } \\
\text { in accessibility in about } 15 \% \text { of the areas with a maxi- } \\
\text { mum decline rate of } 29 \% \text {. }\end{array}$ \\
\hline & Milakis et al. (2018) & $\begin{array}{l}\text { Expert-based experi- } \\
\text { ment and Q method }\end{array}$ & $\begin{array}{l}\text { One view is that the changes in accessibility caused } \\
\text { by } S A V \text { s have great uncertainty. The travel time and } \\
\text { cost savings brought by } S A V \text { s may be offset by the } \\
\text { induced traffic demand generated in the long-term. } \\
\text { Another view is that } S A V \text { s may cause social unfairness } \\
\text { problems. }\end{array}$ \\
\hline & $\begin{array}{l}\text { Papa and Ferreira } \\
\qquad(2018)\end{array}$ & Scenario planning & $\begin{array}{l}\text { Different government decisions will lead to different } \\
\text { impacts of SAVs on accessibility. If SAVs are used } \\
\text { improperly, it will increase residents' dependence on } \\
\text { cars, and further exert negative effects on accessibil- } \\
\text { ity, energy consumption, urban environment, and } \\
\text { residents' health. }\end{array}$ \\
\hline & $\begin{array}{l}\text { Cohen and Cavoli } \\
\qquad(2019)\end{array}$ & $\begin{array}{l}\text { Scenario planning } \\
\text { and experts seminar }\end{array}$ & $\begin{array}{l}\text { If the government does not take any measures, SAVs } \\
\text { will increase the total vehicle miles traveled and traffic } \\
\text { flow, resulting in traffic congestion and reducing the } \\
\text { accessibility of passengers using walking, cycling, and } \\
\text { public transportation. They suggest that the govern- } \\
\text { ment take interventions in five aspects to avoid the } \\
\text { negative impacts of SAVs on accessibility: land use } \\
\text { planning, policies and regulations, infrastructure and } \\
\text { technology, service provision, and economic instru- } \\
\text { ments. }\end{array}$ \\
\hline
\end{tabular}

\subsection{Road congestion pricing in the environment of SAVs}

Road congestion pricing policy has been widely explored in the literature, but only a few studies analyzed road congestion pricing problems in the context of SAVs (Salazar, Rossi, Schiffer, Onder, \& Pa- 
vone, 2018). Besides, the existing literature mainly focused on the short-term effects of road congestion pricing on travelers' travel behaviors (e.g., departure time, travel route, and travel mode) in the environment of SAVs (Faisal, Yigitcanlar, Kamruzzaman, \& Currie, 2019).

Assuming travelers' destinations remain unchanged, Simoni et al. (2019) studied the effects of different road congestion pricing schemes on travelers' mode choices, network performance, and welfare changes in the environment of SAVs using the multi-agent transportation simulation model MATSim. Similarly, using a multinomial logit mode choice model and an agent-based model, Chen and Kockelman (2016) explored the influence of different pricing strategies on mode shares of SAVs and found that network performance can be improved with targeted pricing strategies.

In view of this, some scholars used different models to optimize network performance in the context of SAVs and road congestion pricing. Leveraging a multi-commodity flow-based optimization model, Salazar et al. (2018) founded that by designing a pricing scheme, the system can achieve the social optimum under the assumption of selfish travelers. Besides, based on the macroscopic fundamental diagram theory, Yang, Menendez, and Zheng (2019) proposed a control approach to simultaneously optimize road congestion pricing and perimeter control in the environment of connected vehicles. Tscharaktschiew and Evangelinos (2019) discussed the relationship between the level of autonomous driving (driving mode choice) and road congestion pricing.

In summary, research on the short-term effects of SAVs and road congestion pricing on travelers or transportation system has been extensively studied (de Palma and Lindsey, 2011; Milakis et al., 2017b), while there is little research on the long-term effects of the integration of SAVs and road congestion pricing on regional job accessibility. To maximize the benefits brought by the combination of the two technologies, it is urgent to analyze the above problems in detail from the perspective of land use and transportation integration.

\section{Case study}

\subsection{Regional development scenarios}

This study selected Jiangyin City as the research area. Jiangyin City is located in the south of Jiangsu Province, China, with a total area of about 988 square kilometers. At the end of 2018, the city's permanent population was about 1.65 million. Four regional development scenarios were created in this study. Table 3 describes the characteristics of the four scenarios, namely the trend development scenario (Scenario A), the SAVs development scenario (Scenario S), the road congestion pricing scenario (Scenario $C$ ), and the integration of $S A V$ s and road congestion pricing scenario (Scenario B). The initial year of the land use and transportation integrated model of Jiangyin City is 2010. The model runs every 5 years until 2040. The road congestion pricing policy will be implemented in 2020 and SAVs will be introduced in 2025. In addition, according to Litman's (2018) forecast, the market penetration rate of SAVs by 2040 is about $40 \%$. 
Table 3. Description of the characteristics of four scenarios

\begin{tabular}{|cccc|}
\hline Scenarios & Scenario description & Initial year & Final year \\
\hline A & Trend development scenario & 2010 & 2040 \\
\hline S & SAVs development scenario & 2025 & 2040 \\
\hline C & $\begin{array}{c}\text { Road congestion pricing } \\
\text { scenario }\end{array}$ & 2020 & 2040 \\
\hline B & $\begin{array}{c}\text { SAVs and road congestion } \\
\text { pricing scenario }\end{array}$ & 2025 & 2040 \\
\hline
\end{tabular}

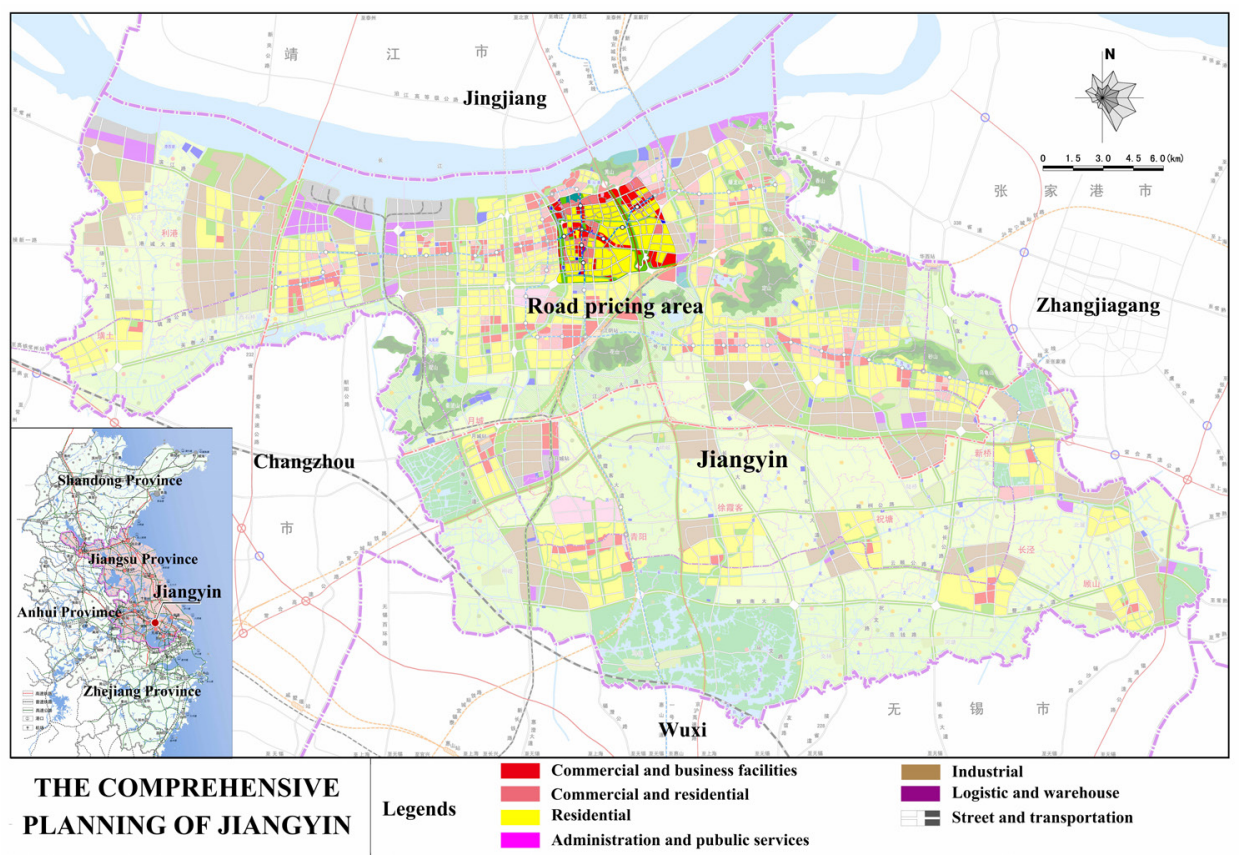

Figure 1. Map of Jiangyin City and the road congestion pricing area

This study adopted the widely used cordon-based pricing, which charges variable or fixed road tolls for vehicles entering the pre-defined congested areas during peak hours (Zhang \& Yang, 2004). The tolled area in this study is the downtown area, as shown in Figure 1. All vehicles except public transportation vehicles, e.g., private cars, SAVs, and trucks, are charged 20 Chinese Yuan (CNY) per time when they enter the charging area.

\subsection{Data sources}

There are three types of data required for the land use and transportation integrated model of Jiangyin City. The first type is the land use data including the land use type, area, price, quantity, population, and the number of jobs in each TAZ, which is obtained from the comprehensive plan of Jiangyin (Jiangsu Institute of Urban Planning and Design, 2011) and the Jiangyin statistical yearbook. The second type is the road and traffic information data, such as road name, type, length, speed limit, capacity, and traffic volume of the main road section during peak hours, which is obtained from the Jiangyin Bureau of Transportation. The third type is the public transportation data including the running time of buses, 
cost, speed, carrying capacity, average passenger load, average waiting time, and fare, which is obtained from the Jiangyin Public Transportation Company.

\section{$4 \quad$ Methodology}

\subsection{Calculation of regional accessibility}

This study chooses job accessibility as an indicator to measure regional accessibility. Job accessibility is defined as the ease of reaching a job at a location by using a range of transportation modes (Geurs \& van Wee, 2004). The indicator consists of two parts, including a weighted variable that describes the number of jobs in a given area and an impedance variable associated with travel time that measures the difficulty of reaching a job from a certain location (Zhong \& Bushell, 2017a). Generally speaking, the closer the area to a large number of jobs, the greater the regional job accessibility, and vice versa. In this study, the calculation of regional job accessibility is formulated as Eq. (1).

$J A_{i}=\sum_{j} J_{j} \cdot T\left(t_{i j}\right)$

where $J A_{i}$ is the job accessibility of TAZ $i ; J_{j}$ is the number of jobs in TAZ $j ; T\left(t_{i j}\right)$ is an impedance function related to travel time between TAZ $i$ and TAZj, as expressed in Eq. (2).

$T\left(t_{i j}\right)=\alpha \cdot e^{\beta+\gamma \cdot t_{i j}}$

where $t_{i j}$ is the shortest travel time between TAZ $i$ and TAZ $j$, which can be achieved by combining different transportation modes; $a, \beta, y$ are the empirically derived impedance parameters whose values, in this study, are $0.001,-0.4,-0.15$, respectively (Cervero \& Kockelman, 1997).

\subsection{Parameter settings of SAVs}

To analyze the impact of the introduction of SAVs on urban land use and transportation systems, the market penetration of SAVs in different years and the corresponding changes in road capacity and travelers' value of time should be determined first. These factors are the input of the land use and transportation integrated model in the next section. The Society of Automotive Engineers (SAE) classified autonomous vehicles into five levels (SAE, 2016). This study focuses on the fourth and fifth levels, i.e., high driving automation and full driving automation.

\subsubsection{Market penetration prediction of SAVs}

Like other vehicle technologies, the initial market penetration of SAVs is low due to the high initial cost of use, but its market penetration would climb with more and more users accepting SAVs due to the decreasing use cost and the increasing performance of SAVs. This study adopted the market penetration of SAVs predicted by Litman (2018) (see Table 4). 


\subsubsection{Impacts of SAVs on road capacity}

Since SAVs have not been widely used, the existing research usually uses simulation analysis and mathematical modeling methods to identify the relationship between SAVs and road capacity under different scenarios (Acheampong \& Silva, 2015; Milakis et al., 2017b; Narayanan et al., 2020). However, it should be pointed out that the independent results have limitations due to the influences of the selected research areas, the adopted methodology, the data, and the model assumptions. To this end, this study used the meta-analysis method to analyze the existing research. Meta-analysis assesses the results of existing research quantitatively and systematically to derive results about that body of the research (Ewing $\&$ Cervero, 2001). Compared with a single independent study, the main advantage of meta-analysis is that it summarizes the existing research results on a certain topic, thus, the results are more general (Ewing $\&$ Cervero, 2010). For a detailed introduction to meta-analysis, the readers are referred to Borenstein, Hedges, Higgins, and Rothstein (2011).

Considering the different perspectives of existing studies and data availability, this study selected the market penetration of SAVs, the road types, and the automation level of SAVs as the influencing factors of road capacity. The road capacity under the influence of SAVs based on the meta-regression model is expressed as Eq. (3).

Capacity $_{\text {rate of change }}=\alpha_{0}+\beta_{1} \cdot$ Penetration $+\beta_{2} \cdot$ Expressway $\beta_{3} \cdot$ Level $+\varepsilon$

where Capacity $y_{\text {rate of change }}$ is the rate of change in road capacity; $\alpha_{0}$ is a constant; Penetration is the predicted market penetration of SAVs given by Litman (2018); Expressway is a dummy variable representing the road type: when Expressway =1, it represents the expressway, when Expressway =0, it represents other urban roads; Level is a dummy variable: when Level =1, it represents SAVs with automation level 4 and 5, when Level $=0$, it represents SAVs with automation level 3 or below; $\varepsilon$ is an error term; $\beta_{1}, \beta_{2}, \beta_{3}$ and are the regression coefficients.

\subsubsection{Impact of SAVs on travelers' value of time}

Similarly, the travelers' value of time under the influence of SAVs is expressed as Eq. (4).

$$
V O T T_{\text {rate of change }}=\alpha_{0}^{\prime}+\beta_{1}^{\prime} \cdot \text { Penetration }+\beta_{2}^{\prime} \cdot \text { Expressway }+\beta_{3}^{\prime} \cdot \text { Level }+\varepsilon^{\prime}
$$

where $V O T T_{\text {rate of change }}$ represents the rate of change in travelers' value of time; $\alpha_{0}^{\prime}$ is a constant; $\varepsilon^{\prime}$ is an error term; $\beta_{1}^{\prime}, \beta_{2}^{\prime}$, and $\beta_{3}^{\prime}$ are the regression coefficients.

Based on the existing research results (Acheampong \& Silva, 2015; Milakis et al., 2017b; Narayanan et al., 2020), using Eq. (3) and Eq. (4), the impact of SAVs on road capacity and travelers' value of time in different years are determined and listed in Table 4. It can be found that by 2040, the market penetration of SAVs will be $40 \%$, the road capacity will increase by $6.78 \%$, and the traveler's value of time will decrease by $23.9 \%$. These results are the inputs of the land use and transportation integrated model, namely the TRANUS model. 
Table 4. The market penetration of SAVs and the corresponding rate of changes in road capacity and travelers' value of time in different years

\begin{tabular}{|cccc|}
\hline Year & $\begin{array}{c}\text { Market penetration of } \\
\text { SAVs }\end{array}$ & $\begin{array}{c}\text { Rate of change in road } \\
\text { capacity }\end{array}$ & $\begin{array}{c}\text { Rate of change in travelers' } \\
\text { value of time }\end{array}$ \\
\hline 2030 & $20.00 \%$ & $2.04 \%$ & $-13.80 \%$ \\
2035 & $30.00 \%$ & $4.41 \%$ & $-18.85 \%$ \\
2040 & $40.00 \%$ & $6.78 \%$ & $-23.90 \%$ \\
\hline
\end{tabular}

\subsection{Establishment and calibration of the integrated model}

\subsubsection{Establishment of the Jiangyin integrated model}

The Jiang integrated model was established by TRANUS. As a land use and transportation integrated model, TRANUS is widely used around the world (de la Barra, Pérez, \& Vera, 1984; Bandeira, Coelho, Sá, Tavares, Borrego 2011; Yuan, Song, Hong, \& Huang, 2017; Zhong, Wang Jiang, Yu, \& Zhang, 2015). Based on random utility theory, TRANUS characterizes a series of behaviors of decision-makers through discrete choice models (de la Barra et al., 1984; Zhong et al., 2015). It assumes that residents are completely rational, namely, residents choose their residence, workplace, travel mode, and travel route according to the principle of maximum expected utility (Zhong et al., 2015). The TRANUS model consists of the land use subsystem and the transportation subsystem. It mainly includes five sub-models: location choice, trip generation, trip distribution, mode split, and traffic assignment. For a detailed introduction to the TRANUS model, the readers are referred to de la Barra et al. (1984). The framework of the Jiangyin integrated model is illustrated in Figure 2.

Land use subsystem. The land use subsystem comprises of two exogenous sectors, i.e., industrial job and government job, and twelve induced sectors, i.e., retail job, entertainment job, health job, education job, population, industrial land, commercial land, residential land, office land, health land, education land, and entertainment land. There is a production-consumption chain relationship between different sectors, as shown in Figure 2. In a typical production-consumption chain, the industrial or government jobs in area $i$ generate a certain population demand. These demanded population will come from different regions. The specific population distribution is determined based on maximum expected utility depending on the distribution of residential land, housing prices, accessibility, and travel cost between residence and workplace. To meet people's various living needs, the population distributed in various regions will also generate demand for various services, requiring a certain amount of service jobs, such as retail jobs, entertainment jobs, health jobs, and education jobs. The service jobs create population demand in turn. The above-mentioned processes finally reach an equilibrium state, the results of which are input into the transportation subsystem.

Transportation subsystem. The production-consumption process between different land use sectors generates two types of trips, commuting trips and service trips. The transportation subsystem includes six modes of transportation, i.e., walking, cycling, rail transit, bus, SAV, and private car. Travelers choose their transportation mode with the maximum expected utility according to the use costs of various transportation modes. From the origin to the destination, travelers can use one transportation mode or a combination of several different transportation modes. For example, travelers can first take a SAV to the bus stop and then take public transportation to the destination.

In summary, the land use subsystem changes the state of the transportation subsystem by affecting travel demand, and the transportation subsystem, in turn, affects the type and distribution of land use 
through accessibility and travel costs. The two subsystems fed back circularly until they reach an equilibrium state.

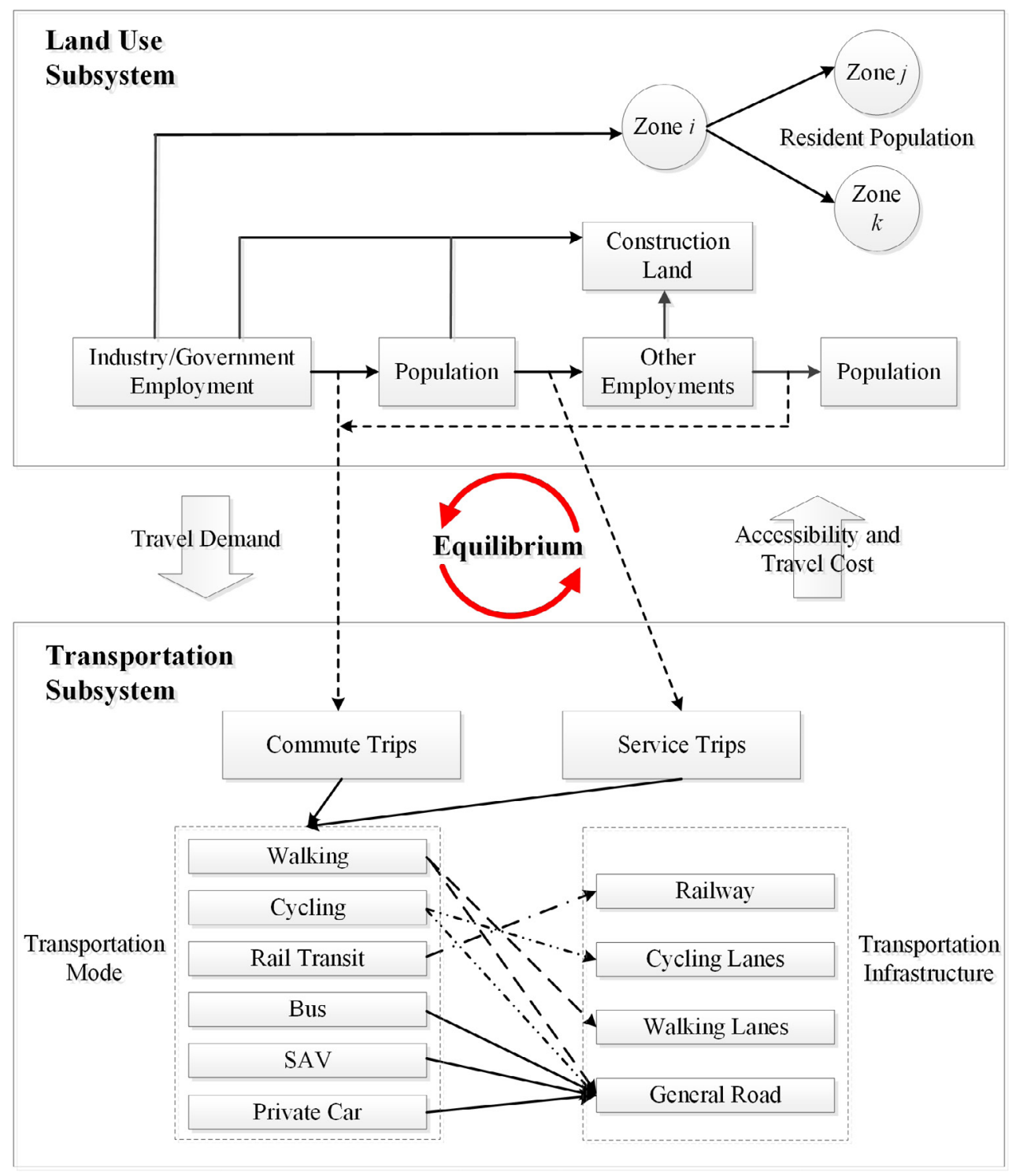

Figure 2. The framework of the Jiangyin integrated model

\subsubsection{Calibration of the Jiangyin integrated model}

Considering that the relationship between the land use subsystem and the transportation subsystem is complex and also the integrated model has many parameters, this study adopted the piecewise estimation approach to calibrate the Jiangyin integrated model (Abraham \& Hunt, 2000). The specific steps are as follows:

- First, calibrate the land use subsystem as a stand-alone application;

- Second, the transportation subsystem is then calibrated based on the results obtained from the land use subsystem; 
- Finally, the correlation parameters of the two subsystems are calibrated using the complete land use and transportation integrated model.

The base year for the Jiangyin integrated model is 2010. Different parameters were selected as the convergence evaluation criteria for the land use subsystem and the transportation subsystem.

Calibration results of the land use subsystem. Considering the data availability and accuracy of the comprehensive planning of Jiangyin City, the layout and scale of industrial land, retail land, and residential land were selected as the evaluation parameters. After repeated debugging, the convergence accuracy of each land use sector is within 1\%, which meets the calculation accuracy requirement.

Calibration results of the transportation subsystem. The mode share of different transportation modes and the traffic flow of main road sections were selected as the evaluation parameters. In the basic year, there are four transportation modes, i.e., walking, non-motorized vehicle, bus, and private car. Taking into account the division scale of TAZs, walking is regarded as a feeder of other transportation modes, whose travel volume is not included in the total travel volume. According to the travel survey of Jiangyin City in 2010, the mode shares of non-motorized vehicle, bus, and private car are $33.5 \%$, $22.1 \%$, and $44.4 \%$, respectively. The corresponding mode shares simulated by the Jiangyin integrated model are $33.3 \%, 21.3 \%$, and $45.45 \%$. It can be calculated that the deviations between the survey value and the simulated value of the mode shares are $-0.6 \%, 3.62 \%$, and $2.25 \%$, respectively. Besides, five main road sections were selected to observe the peak hour cross-section traffic flow, and the maximum error of each observation point is within $8 \%$. Therefore, the prediction results of the Jiangyin integrated model can be considered reliable.

\subsection{Classification of traffic analysis zones}

The basic analysis unit of this study is TAZ. Considering the size of the study area, the whole area was divided into 265 TAZs, among which 56 are tolled TAZs and 209 are non-tolled TAZs. The area of the tolled TAZs is about $13 \mathrm{~km}^{2}$. To analyze the spatial heterogeneity of the effects of the integration of SAVs and road congestion pricing on the job accessibility in areas with different built environment attributes, this study used data mining technology, i.e., factor analysis and clustering analysis to quantitatively classify 265 TAZs (Zhong et al., 2015; Zhang, Sun, Shen, \& Zhu, 2017).

To reduce the multicollinearity between different variables and decrease the number of original variables, factor analysis was adopted to compress the original built environment variables (Child, 2006). Principal components analysis was used to extract the factors, among which whose characteristic value greater than 1 was chosen as an effective factor. The varimax orthogonal rotation was used to rotate the factors. Based on this method, seven basic factors were extracted for 56 tolled TAZs and 209 non-tolled TAZs, respectively (see Figure 6 and Figure 8).

Taking the basic factors extracted based on factor analysis as input, K-means clustering analysis was employed to quantitatively classify TAZs within and outside the toll ring. The basic principle of Kmeans clustering analysis is to minimize the internal distinctions of each TAZ type, while maximizing the external dissimilarities to other TAZ types. The purpose of classifying TAZs is to measure and distinguish different TAZs more accurately and discover the spatial heterogeneity of the effects of SAVs and road congestion pricing on the job accessibility in regions with different built environment attributes. Detailed results for the factor analysis and the clustering analysis can be found in the appendices A and $\mathrm{B}$, respectively. 


\subsubsection{Results of clustering analysis of TAZs outside the toll ring}

Considering the statistical results and interpretability of clustering analysis, TAZs outside the toll ring were divided into eight types (See Figure 6). The different colors in Figure 6 represent different built environment attributes. The higher the value, the better the built environment attribute, and vice versa. Form Figure 6, we can realize the difference between different types of TAZs. The specific attributes of different types of TAZs outside the toll ring are summarized as follows:

TAZs of type 1 are close to the city center and have a large amount of population.

TAZs of type 2 are the farthest from the city center and all the built environment attributes are bad.

TAZs of type 3 are the residential center in the suburbs of the city. The street design and bus transportation conditions are not ideal, but the other built environment attributes are good.

TAZs of type 4 are the industrial center on the outskirts of the city. The street design, bus transportation condition, and infrastructure accessibility are very good.

TAZs of type 5 are the commercial center close to the road pricing area. The TAZs in this group have the largest number of retail jobs.

TAZs of type $\mathbf{6}$ are the administrative center close to the toll zone. The infrastructure accessibility, street design, and bus transportation condition are good, while these TAZs lack retail jobs, industrial jobs, and population.

TAZs of type 7 are the industrial center. The built environment attributes except industrial jobs are poor.

TAZs of type 8 have good infrastructure accessibility, while the rest of the built environment attributes are bad.

\subsubsection{Results of clustering analysis of TAZs within the toll ring}

Similarly, we divided the TAZs within the toll ring into eight categories. Figure 8 illustrates the difference between different types of TAZs. The specific attributes of different types of TAZs within the toll ring are summarized as follows:

TAZs of type 1 have good infrastructure accessibility, but the other built environment attributes are bad.

TAZs of type 2 have good retail job and bus transportation conditions, while the infrastructure accessibility condition is the worst.

TAZs of type 3 have the best street design and infrastructure accessibility conditions. The retail job and bus transportation conditions are also good.

TAZs of type 4 are the administrative center with the largest number of government jobs. 
TAZs of type 5 are the industrial center with good conditions of retail job and bus transportation.

TAZs of type 6 have good street design and the largest number of industrial jobs, but the retail and bus conditions are the worst.

TAZs of type 7 have the best conditions of retail and bus transportation. However, the conditions of population, government jobs, and street design are the worst.

TAZs of type 8 belong to the residential center in the downtown area with the largest amount of population.

\section{$5 \quad$ Results analysis}

\subsection{Land use and transportation systems analysis}

There is an interactive feedback relationship between urban land use and transportation systems, but their response time to each other's influence is different. Changes in the land use system will have an immediate impact on the transportation system, but the impact of the transportation system on the land use system gradually appears over time. In the context of this study, the introduction of road congestion pricing and SAVs will have an immediate impact on the transportation system, but the impact on the land use system will lag. As mentioned in section 3.1, road congestion pricing is going to be implemented in 2020 and SAVs will be introduced in 2025. In view of this, this study took the land use and transportation data in 2040 as the basis for analysis, so the effects of SAVs and road congestion pricing can be fully presented.

\subsubsection{Analysis of population and jobs under different scenarios}

Table 4 presents the overall statistics of the population and the number of jobs in the toll ring and the whole study area for each scenario in 2040. Figure 3 shows the rates of changes in the number of jobs and population within the toll ring under different scenarios compared with Scenario A. The rate of changes is calculated using Eq. (5).

$$
\alpha_{i}(y)=\left[P_{i}(y) / O_{i}(y)\right] /\left[P_{i}(\mathrm{~A}) / O_{i}(\mathrm{~A})\right], i=1,2
$$

where $\alpha_{i}(y)$ represents the rate of changes in the number of jobs or the number of population in TAZs within the toll ring under a certain scenario $y$, i.e., Scenario S, Scenario C, Scenario B, compared with Scenario A. Note that when the subscript is 1 , the variable is associated with the feature of jobs, while when the subscript is 2 , the variable is related to the feature of population. $P_{i}(y)$ represents the number of jobs or population in TAZs within the toll ring under a certain scenario $y$, i.e., Scenario $S$, Scenario C, Scenario B. $P_{i}($ A) represents the number of jobs or population in TAZs within the toll ring under Scenario A. $O_{i}(y)$ represents the total number of jobs or population in the whole study area under a certain scenario $y$, i.e., Scenario S, Scenario C, Scenario B. $O_{i}($ A) represents the total number of jobs or population in the whole study area under Scenario A. According to Table 4 and Figure 3, it can be found that:

- Overall, it is more convenient for travelers due to the emergence of SAVs (Scenario S). The increased proportion of the number of jobs and population within the toll ring indicates that the 
introduction of SAVs promotes the development of the downtown area. Specifically, compared with the trend development scenario (Scenario A), the introduction of SAVs makes the rate of changes in the number of jobs and population within the toll ring increase to $104.06 \%$ and $127.35 \%$ by 2040 , respectively.

- For the road congestion pricing scenario (Scenario C), the number of jobs and population within the toll ring will decline to some extent due to the increase in travel costs. This indicates that the road congestion pricing policy makes the region spread outward and inhibits the development within the toll ring, which is consistent with the previous research results (Zhong et al., 2015; Zhong \& Bushell, 2017a). Specifically, compared with the trend development scenario (Scenario A), when the road congestion fee is $20 \mathrm{CNY}$, the rate of changes in the number of jobs and population within the toll ring will decline to $97.22 \%$ and $80.11 \%$ by 2040 , respectively.

- From Figure 3, we can see that the introduction of SAVs can counter the negative impact of road congestion pricing on the number of jobs and population within the toll ring to a certain extent. Compared with the trend development scenario (Scenario A), the combination of SAVs and road congestion pricing (Scenario B) can increase the number of jobs and population within the toll ring. The combined effect is between the effect of Scenario $S$ and Scenario C.

Table 4. Conditions of jobs and population in 2040 under different scenarios

\begin{tabular}{|ccccc|}
\hline & & $\begin{array}{c}\text { The total amount in } \\
\text { the whole study area }\end{array}$ & $\begin{array}{c}\text { The total amount } \\
\text { within the toll ring }\end{array}$ & Percentage of all \\
\hline \multirow{2}{*}{ Scenario A } & Jobs & 159626 & 88818 & $5.56 \%$ \\
& Population & 3468675 & 283614 & $8.18 \%$ \\
Scenario S & Jobs & 1605130 & 92420 & $5.76 \%$ \\
& Population & 3487946 & 361195 & $10.36 \%$ \\
Scenario C & Jobs & 1596261 & 86350 & $5.41 \%$ \\
& Population & 3468676 & 227197 & $6.55 \%$ \\
Scenario B & Jobs & 1605129 & 91167 & $5.68 \%$ \\
& Population & 3487947 & 336745 & $9.65 \%$ \\
\hline
\end{tabular}

Note: Percentage of all $=$ The total amount within the toll ring/The total amount in the whole study area.

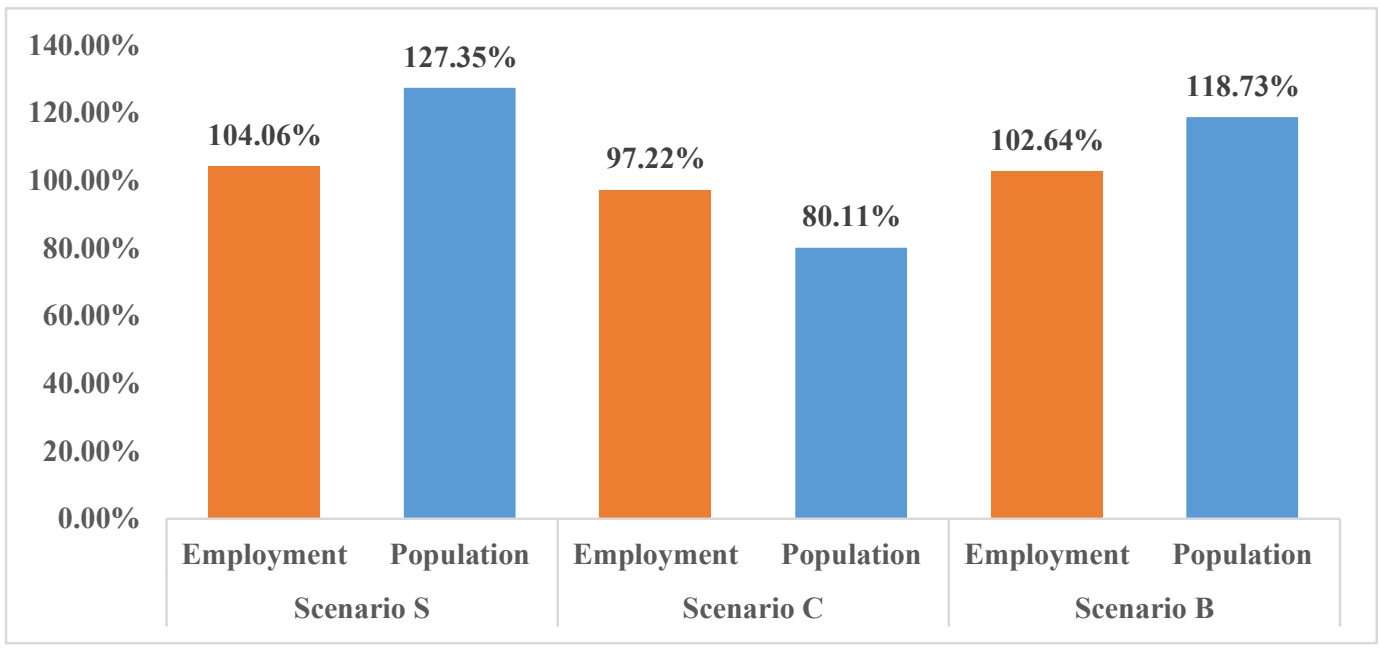

Figure 3. Rate of changes in jobs and population within the toll ring in 2040 under different scenarios compare with Scenario A 


\subsubsection{Analysis of average travel time under different scenarios}

The travel time between 265 TAZs can be obtained by the land use and transportation integrated model. Based on this, the average travel time between different TAZs under different scenarios can be calculated using Eq. (6).

$\bar{T}_{x y}=\sum_{i} \sum_{j} t_{i j} / k^{2}$

where $\bar{T}_{x y}$ is the average travel time between different TAZs in year $x$ under scenario $y . t_{i j}$ represents the shortest travel time between TAZ $i$ and TAZ $j . k$ indicates the number of TAZs.

Figure 4 presents the average travel time between TAZs in different years $(2030,2035$, and 2040) and scenarios. From Figure 4, it can be seen that no matter under which scenario, the average travel time between TAZs has increased as time goes by. Comparing the four scenarios, from the perspective of reducing the average travel time between TAZs, Scenarios $S$ (introducing SAVs alone) has the best positive effect, followed by Scenario B (integration of SAVs and road congestion pricing), while Scenario $\mathrm{C}$ (implementing road congestion pricing alone) has the least positive effect.

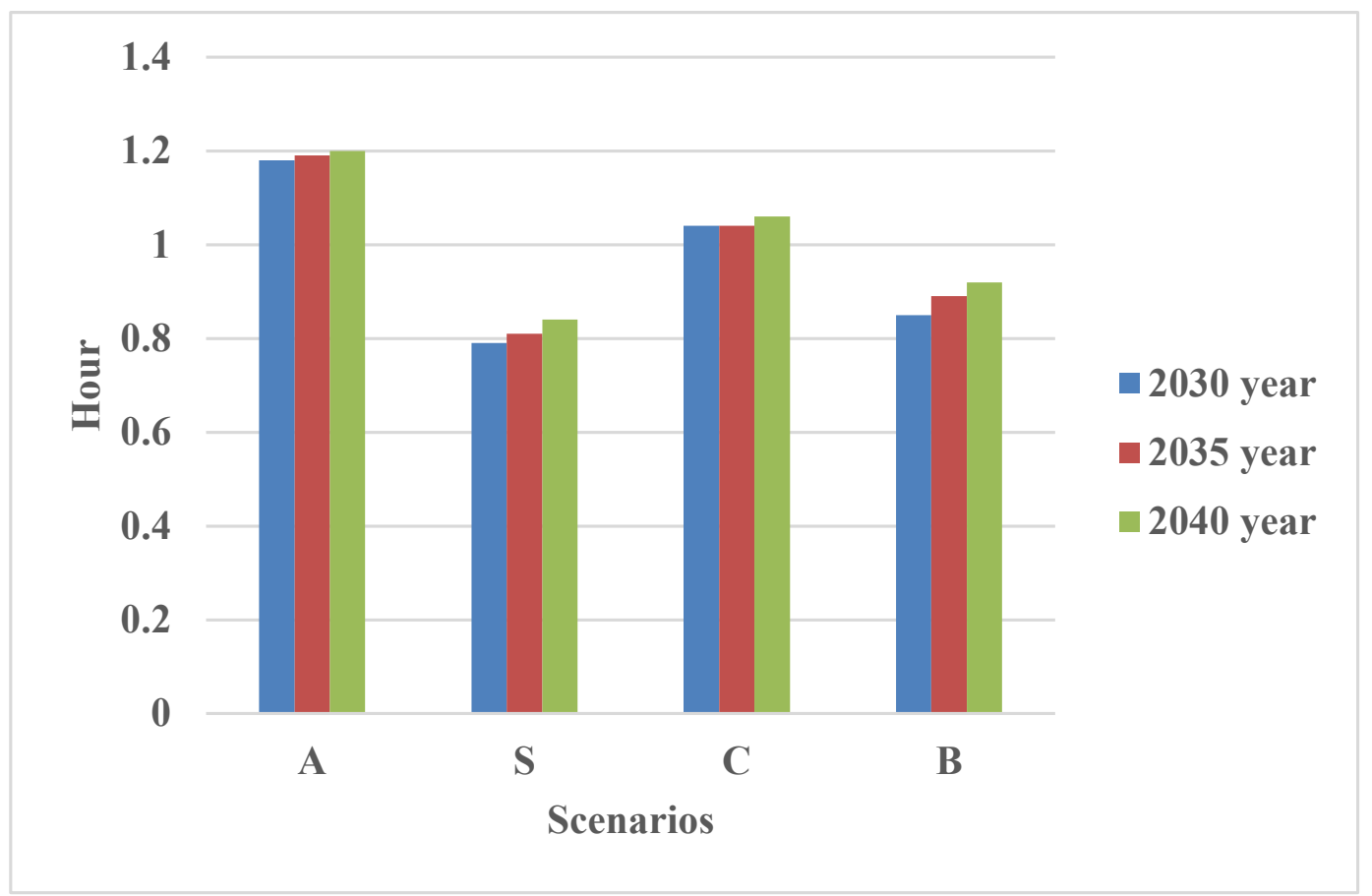

Figure 4. Average travel time between TAZs in different years and scenarios

\subsection{Analysis of job accessibility}

This section analyzes the changes in job accessibility under different scenarios and answers the following questions: (1) Which technology has a better effect on promoting regional job accessibility, the introduction of SAVs or the implementation of road congestion pricing? What is the effect of the combination of the two technologies? (2) Is there any difference in the impact of the integration of SAVs and road congestion pricing on the job accessibility in TAZs of different types? Which type of TAZs is more 
negatively affected?

To better understand the effects of the two technologies inside and outside the toll ring, this study discusses their impacts separately. In addition, to analyze the combined impact of SAVs and road congestion pricing on regional job accessibility, this study introduces the index of the change rate of job accessibility, as formulated in Eq. (7).

$\beta_{k}=\left[\overline{J A_{k}}(\mathrm{~B})-\overline{J A_{k}}(\mathrm{~A})\right] / \overline{J A_{k}}(\mathrm{~A})$

where $\beta_{k}$ is the change rate of job accessibility in TAZs of type $k$ under Scenario B compared with Scenario A; $\overline{J A_{k}}(\mathrm{~B})$ is the average job accessibility in TAZ type $\mathrm{k}$ under Scenario $\mathrm{B} ; \overline{J A_{k}}(\mathrm{~A})$ is the average job accessibility in TAZ type $k$ under Scenario A.

\subsubsection{Results analysis of TAZs outside the toll ring}

Figure 5 shows the changes in job accessibility in different types of TAZs outside the toll ring under different development scenarios in 2040. Figure 6 presents the classification results of the TAZs outside the toll ring. Table 5 shows the rate of change in regional job accessibility under Scenario B, compared to regional job accessibility under Scenario A. The following conclusions can be made from Figure 5 and Table 5:

- Outside the toll ring, if we compare the job accessibility of different scenarios with that of Scenario A, we can find that Scenario $S$ has the best job accessibility in all types of TAZs except TAZ type 3, followed by Scenario B, while Scenario C has the worst job accessibility. It can be seen from the analysis in Section 5.1 that, compared with other scenarios, the implementation of SAVs technology alone makes the total number of jobs in the region increase the most and the average travel time decrease the most. According to the regional job accessibility calculation formula (1), when SAVs are implemented alone, the job accessibility outside the toll ring increases the most.

- The combination of SAVs and road congestion pricing does not generate extra benefits in job accessibility in TAZs outside the toll ring. Namely, the effect of introducing SAVs alone is better than that of the combination of the two technologies.

- It can be seen from Table 5 that, compared with the trend development scenario, after the integrated use of SAVs and road congestion pricing, the change rate of job accessibility in TAZ type 2 is the highest. According to Figure 6, TAZs of type 2 are the farthest from the city center and all of the built environment attributes in these TAZs are bad. Therefore, the introduction of SAVs could greatly improve the convenience of regional transportation of TAZ type 2, and the regional job accessibility has been improved the most.

- In contrast, compared with the trend development scenario, after the introduction of both SAVs and road congestion pricing, TAZ type 6 is the only area whose job accessibility has declined. On the one hand, the area is at the peripheral boundary of the toll ring. Due to the boundary effect (Banister, 2003), travel time goes up and accessibility goes down. On the other hand, although the area belongs to the administrative center, the retail job and industrial job conditions are very bad, which influences the job accessibility in the region.

- For areas outside the toll ring, the impact of road congestion pricing (Scenario C) on regional job accessibility is affected by the built environment attributes of each TAZ. Besides, the impact on TAZs with different built environment attributes is not the same, which is consistent with the results of Zhong and Bushell (2017a). 


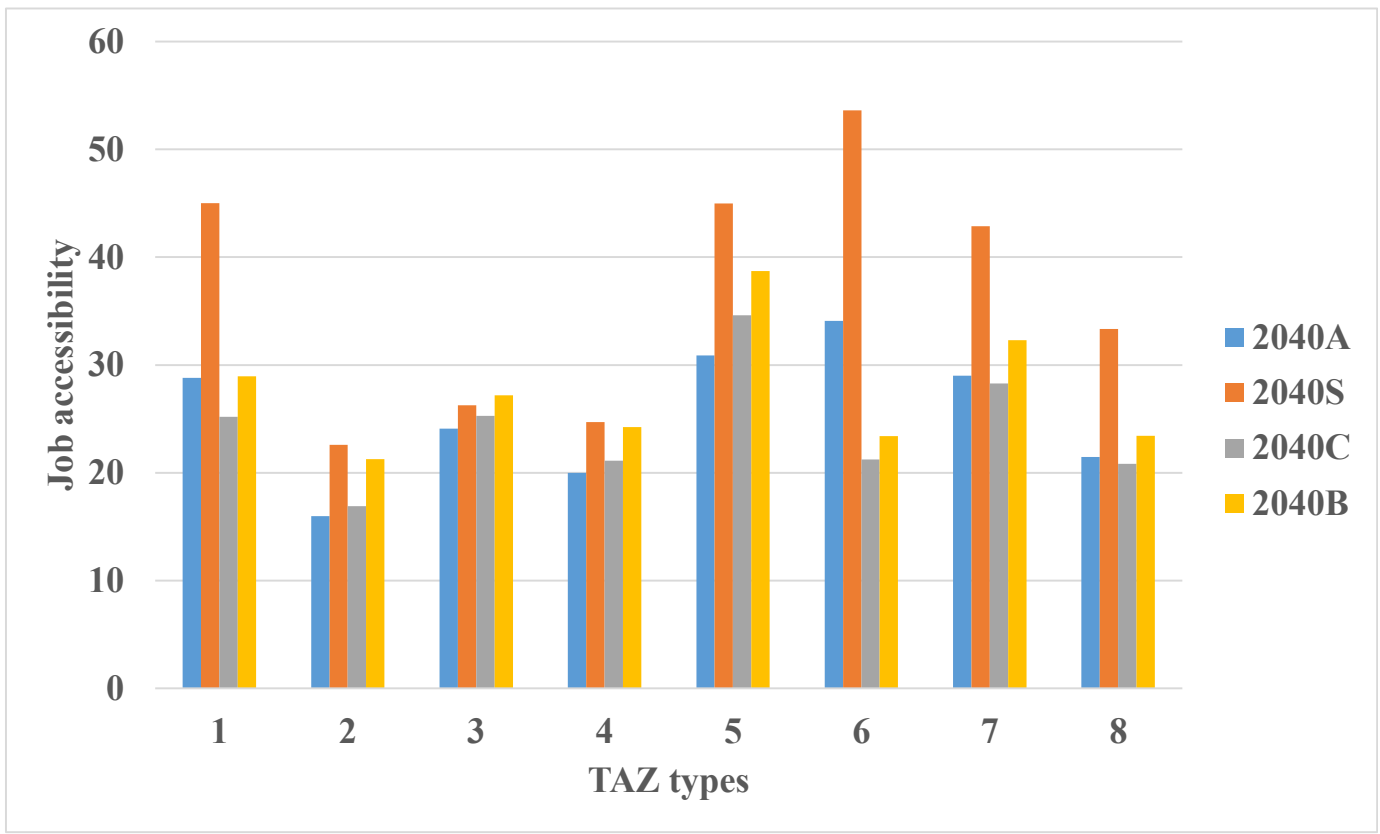

Figure 5. Changes in job accessibility in different types of TAZs outside the toll ring under different development scenarios in 2040

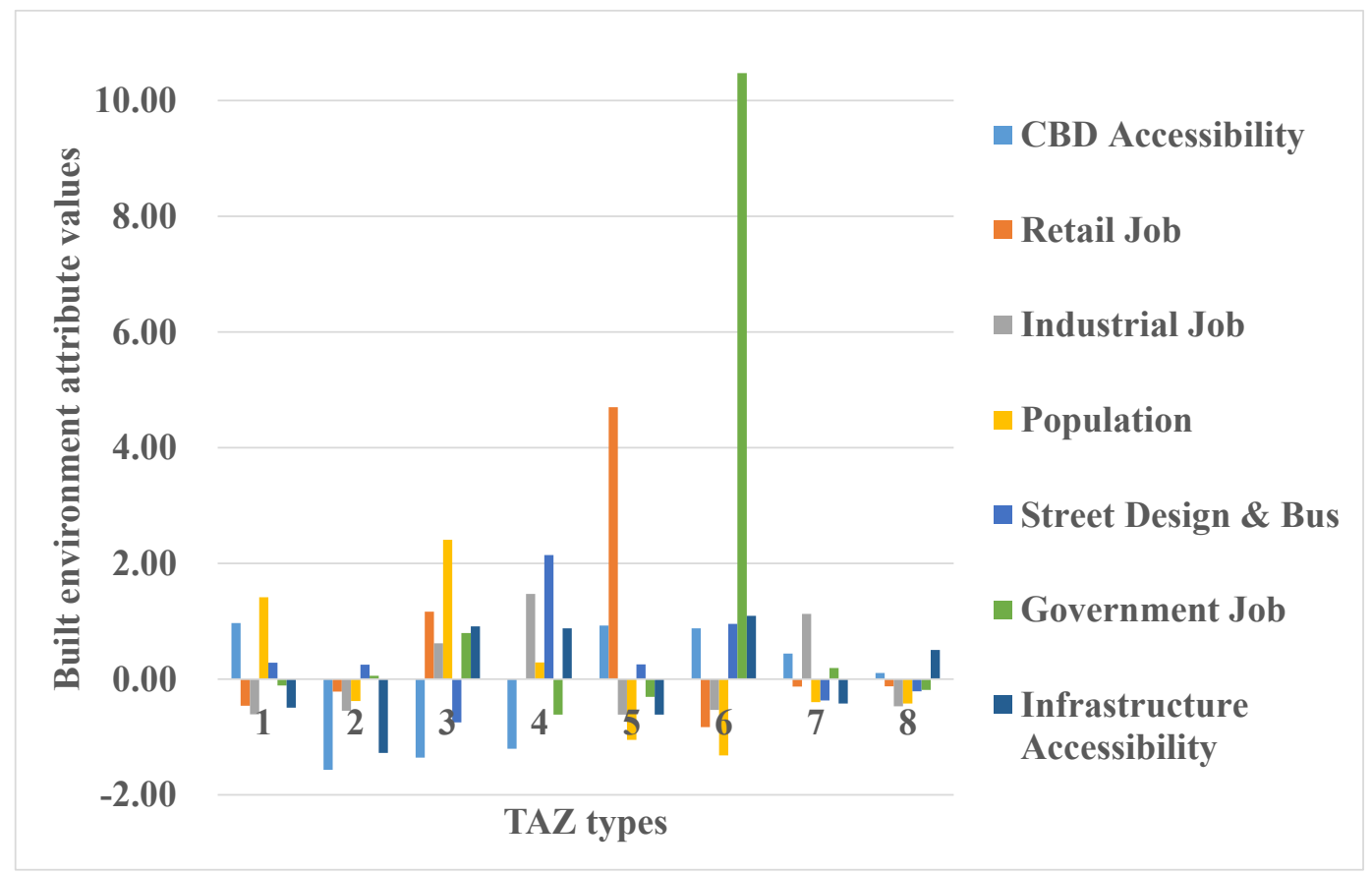

Figure 6. Classification results of the TAZs outside the toll ring 
Table 5. Change rate of job accessibility in different types of TAZs outside the toll ring under Scenario B compared with Scenario A

\begin{tabular}{|cc|}
\hline TAZ type & Rate of change in job accessibility $\boldsymbol{\beta}_{\boldsymbol{k}}(\mathbf{\%})$ \\
\hline 1 & 0.45 \\
2 & $\mathbf{3 3 . 0 8}$ \\
3 & 12.81 \\
4 & 21.25 \\
5 & 25.32 \\
6 & -31.37 \\
7 & 11.34 \\
8 & 9.06 \\
\hline
\end{tabular}

Note: The bold values present the most positively affected TAZ types, while the values displayed in dark and bold show the most adversely affected TAZ types.

\subsubsection{Results analysis of TAZs within the toll ring}

The variations of job accessibility in different types of TAZs within the toll ring under different development scenarios in 2040 are shown in Figure 7. Figure 8 presents the classification results of the TAZs within the toll ring. The change rate of job accessibility in TAZs within the toll ring under Scenario B, compared with that under Scenario A, is listed in Table 6. From Figure 7, the following points can be concluded:

- Within the toll ring, compared with regional job accessibility of Scenario A, job accessibility in TAZs of all types except TAZ type 6 has been promoted, no matter under Scenario S, Scenario C, or Scenario B. The effect of SAVs is better than that of road congestion pricing. According to the analysis in Section 5.1, compared with other scenarios, the implementation of SAVs technology has resulted in the largest increase in the number of jobs within the toll ring, and the largest decrease in the average travel time. Thus, the implementation of SAVs alone makes the job accessibility within the toll ring increase the most. The results of the effect of road congestion pricing (Scenario C) is in line with the existing study (Zhong \& Bushell, 2017a).

- An interesting point to note is that compared with implementing one technology alone, the combination of introducing SAVs and road congestion pricing makes the job accessibility in all TAZs reduced, which indicates that the two technologies restrict each other. The possible reason is that the single implementation of road congestion pricing contributes to the shift of jobs within the toll ring to the areas outside the toll ring and the decrease of travel time within the toll ring (Zhong \& Bushell, 2017a). However, when SAVs and road congestion pricing are implemented simultaneously, in addition to the outward shifts of jobs within the toll ring, the number of vehicles inside the toll ring has increased due to the reduced congestion fee shared by the users of SAVs, resulting in the increased travel time within the toll ring. Ultimately, the job accessibility within the road pricing area is decreased.

- The combined effect of SAVs and road congestion pricing on job accessibility is closely related to the street design and industrial job conditions in the region. The better the street design (the greater the number of intersections and the higher the street density) and the greater the number of industrial jobs, the least effective of the combination of SAVs and road congestion pricing. Otherwise, the worse the street design and the fewer the number of industrial jobs, the better the positive combined effects of the two technologies.

- For example, from Table 6 and Figure 8, we can see that the street design in TAZ type 3 is good 
so that the combination of SAVs and road congestion pricing does not improve the job accessibility in these areas significantly. Similarly, the job accessibility in TAZ type 6 declines after the introduction of SAVs and road congestion pricing since these areas have good street design and the greatest number of industrial jobs. In contrast, although there are a few industrial jobs in TAZs of type 5 and type 7, the street design is the worst. Therefore, the job accessibility in these areas goes up greatly.

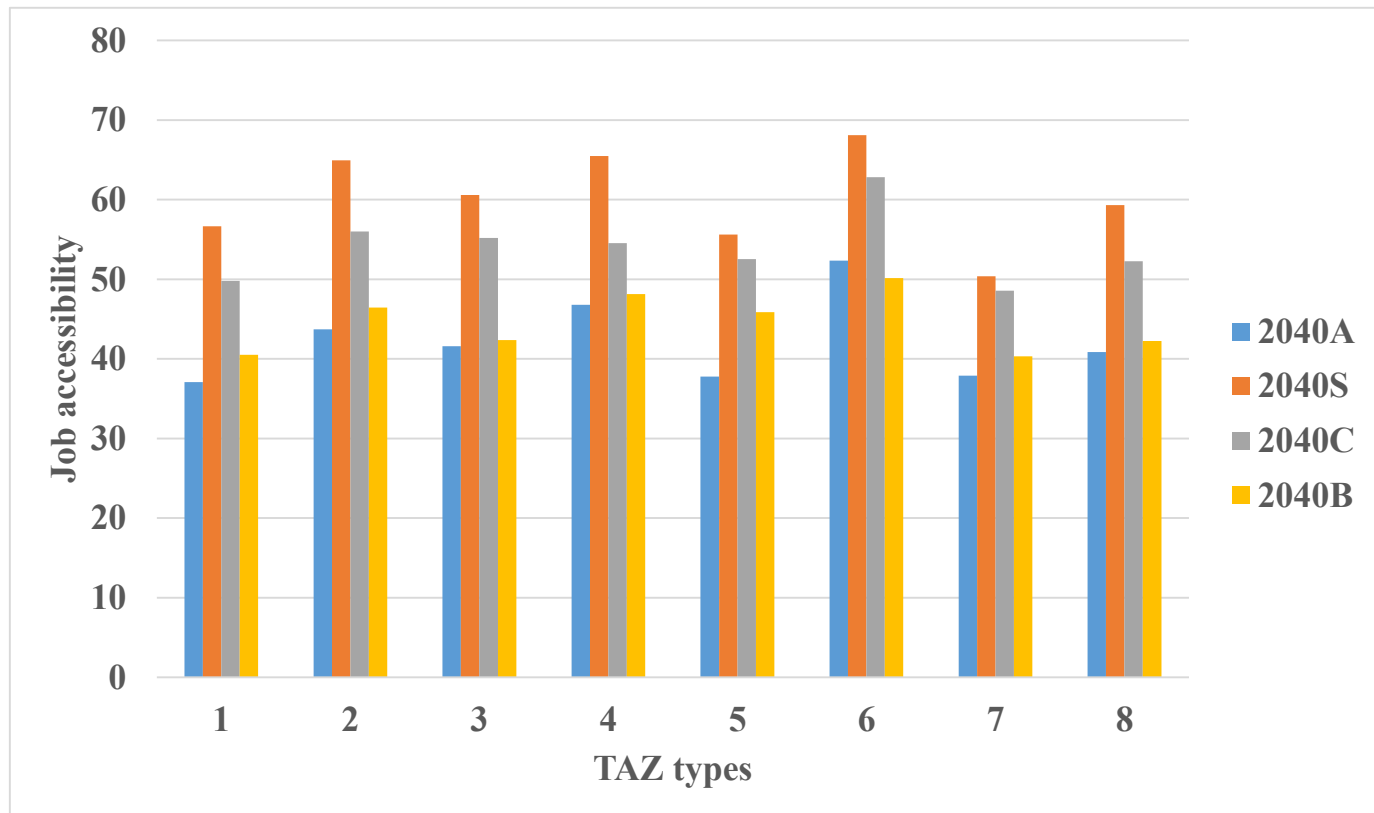

Figure 7. Changes in job accessibility in different types of TAZs within the toll ring under different development scenarios in 2040

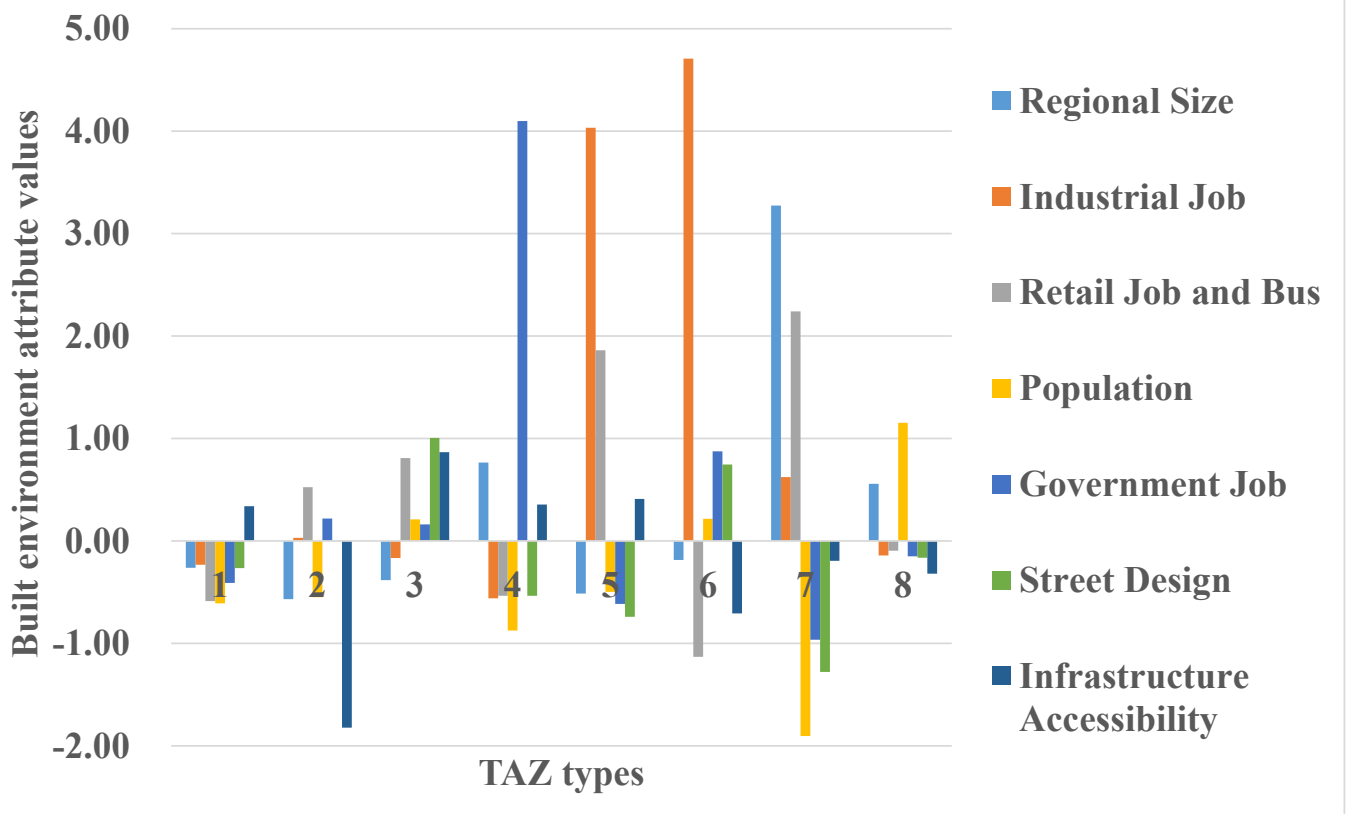

Figure 8. Classification results of the TAZs within the toll ring 
Table 6. Change rate of job accessibility in different types of TAZs within the toll ring under Scenario B compared with Scenario A

\begin{tabular}{|cc|}
\hline TAZ type & Rate of change in job accessibility $\boldsymbol{\beta}_{\boldsymbol{k}}(\%)$ \\
\hline 1 & 9.30 \\
2 & 6.20 \\
3 & 1.85 \\
4 & 2.83 \\
5 & $\mathbf{2 1 . 4 2}$ \\
6 & $\mathbf{- 4 . 1 4}$ \\
7 & 6.45 \\
8 & 3.34 \\
\hline
\end{tabular}

Note: The bold values express the most positively affected TAZ types, while the values which are displayed in dark and bold indicate the most adversely affected TAZ types.

\section{Conclusion}

Most of the existing research on SAVs and road congestion pricing policy explored their short-term impacts on mobility, such as residents' travel behaviors and traffic flow. However, little attention has been paid to deeply explore their long-term impact on accessibility. What's more, due to the neglect of the interactive feedback relationship between urban land use and transportation, the existing research framework is unable to comprehensively analyze the long-term impact of the combination of the two technologies on regional accessibility. To fill this research gap, from the perspective of land use and transportation integration, this study examined the long-term effect of SAVs and cordon-based congestion pricing on land use, transportation, and job accessibility based on the land use and transportation integrated model, scenario planning, and data mining technology.

The main policy implications of this study are summarized as follows:

First, from the perspective of regional land use, this study found that cordon-based congestion pricing contributes to the downtown sprawl and inhibits the development within the toll ring. This conclusion is consistent with Zhong et al. (2015). In contrast, the emergence of SAVs will make it easier for residents to travel and promote the development of jobs and population in the road congestion pricing area. On the other hand, from the perspective of reducing the average travel time between regions, the introduction of SAVs has the best positive effect, followed by the combination of SAVs and road congestion pricing, while the road congestion pricing policy has the worst effect.

Second, in terms of promoting regional job accessibility, the impact of SAVs is better than that of cordon-based congestion pricing. The combination of the two technologies is not as good as implementing SAVs technology alone. Specifically, for the TAZs outside the toll ring, compared with implementing SAVs alone, the integration of SAVs and road congestion pricing does not generate an extra positive effect on job accessibility. For the TAZs within the toll ring, compared with the effect of implementing one technology alone, the job accessibility declines when SAVs and road congestion pricing are implemented simultaneously, which indicates that the effect of these two technologies is restricted to each other.

Last, there are differences in the impact of the integration of SAVs and cordon-based congestion pricing on job accessibility in different types of TAZs. The impact is affected by the built environment 
attributes of the region. This study found that the combined effect of the two technologies on job accessibility in TAZs within the toll ring is closely associated with the street design and the number of industrial jobs. Specifically, the better the street design (the greater the number of intersections and the higher the street density) and the greater the number of industrial jobs, the worse the promoting effect of the integration of SAVs and road congestion pricing on regional job accessibility, and vice versa.

\section{Acknowledgment}

This research has been supported by the National Natural Science Foundation of China (Project No. 71701030 and 71971038), the Humanities and Social Sciences Youth Foundation of the Ministry of Education of China (Project No. 17YJCZH265), China Postdoctoral Science Foundation (Project No. 2018T110223 and 2016M601313), and the Fundamental Research Funds for the Central Universities of China (Project No. DUT20GJ210).

\section{Data availability statement}

All data and code generated or used during the study are confidential. All these items are part of a project with the Jiangsu Institute of Urban Transport Planning, so they are not allowed to be shared.

\section{Appendices}

Appendix A. Factor analysis: https://www.jtlu.org/index.php/jtlu/article/view/1692/1496

Appendix B. Cluster analysis of TAZs: https:/www.jtlu.org/index.php/jtlu/article/view/1692/1497 


\section{References}

Abraham, J. E., \& Hunt, J. D. (2000). Parameter estimation strategies for large-scale urban models. Transportation Research Record, 1722(1), 9-16.

Acheampong, R. A., \& Silva, E. (2015). Land use-transport interaction modeling: A review of the literature and future research directions. Journal of Transport and Land use, 8(3), 11-38.

Bandeira, J. M., Coelho, M. C., Sá, M. E., Tavares, R., \& Borrego, C. (2011). Impact of land use on urban mobility patterns, emissions and air quality in a Portuguese medium-sized city. Science of The Total Environment, 409(6), 1154-1163.

Banister, D. (2003). Critical pragmatism and congestion charging in London. International Social Science Journal, 55(176), 249-264.

Bischoff, J., \& Maciejewski, M. (2016). Simulation of city-wide replacement of private cars with autonomous taxis in Berlin. Procedia Computer Science, 83, 237-244.

Borenstein, M., Hedges, L. V., Higgins, J. P., \& Rothstein, H. R. (2011). Introduction to meta-analysis. Hoboken, NJ: John Wiley \& Sons.

Cervero, R., \& Kockelman, K. (1997). Travel demand and the 3Ds: Density, diversity, and design. Transportation Research Part D: Transport and Environment, 2(3), 199-219.

Chen, T. D., \& Kockelman, K. M. (2016). Management of a shared autonomous electric vehicle fleet: Implications of pricing schemes. Transportation Research Record, 2572(1), 37-46.

Chen, Z., He, F., Yin, Y., \& Du, Y. (2017). Optimal design of autonomous vehicle zones in transportation networks. Transportation Research Part B: Methodological, 99, 44-61.

Child, D. (2006). Essentials of factor analysis (3rd edition). New York: Continuum International.

Childress, S., Nichols, B., Charlton, B., \& Coe, S. (2015). Using an activity-based model to explore the potential impacts of automated vehicles. Transportation Research Record: Journal of the Transportation Research Board, 2493, 99-106.

Cohen, T., \& Cavoli, C. (2019). Automated vehicles: Exploring possible consequences of government (non)intervention for congestion and accessibility. Transport Reviews, 39, 129-151.

de la Barra, T., Pérez, B., \& Vera, A. N. (1984). TRANUS-J: Putting large models into small computers. Environment and Planning B: Planning and Design, 11(1), 87-101.

de Palma, A., \& Lindsey, R. (2011). Traffic congestion pricing methodologies and technologies. Transportation Research Part C: Emerging Technologies, 19(6), 1377-1399.

Ewing, R., \& Cervero, R. (2001). Travel and the built environment: A synthesis. Transportation Research Record: Journal of the Transportation Research Board, 1780(1), 87-114.

Ewing, R., \& Cervero, R. (2010). Travel and the built environment: A meta-analysis. Journal of the American Planning Association, 76(3), 265-294.

Ewing, R., Schmid, T., Killingsworth, R., Zlot, A., \& Raudenbush, S. (2008). Relationship between urban sprawl and physical activity, obesity, and morbidity. In Urban Ecology (pp. 567-582). Boston, MA: Springer.

Fagnant, D. J., \& Kockelman, K. M. (2014). The travel and environmental implications of shared autonomous vehicles, using agent-based model scenarios. Transportation Research Part C: Emerging Technologies, 40, 1-13.

Fan, Y., \& Khattak, A. J. (2008). Urban form, individual spatial footprints, and travel: Examination of space-use behavior. Transportation Research Record, 2082(1), 98-106.

Faisal, A., Yigitcanlar, T., Kamruzzaman, M., \& Currie, G. (2019). Understanding autonomous vehicles: A systematic literature review on capability, impact, planning and policy. Journal of Transport and Land Use, 12(1), 45-72. 
Geurs, K. T., \& van Wee, B. (2004). Accessibility evaluation of land-use and transport strategies: Review and research directions. Journal of Transport Geography, 12(2), 127-140.

Gong, S., Shen, J., \& Du, L. (2016). Constrained optimization and distributed computation based car following control of a connected and autonomous vehicle platoon. Transportation Research Part B: Methodological, 94, 314-334.

Heinrichs, D. (2016). Autonomous driving and urban land use. In M. Maurer, J. Gerdes, B. Lenz, \& H. Winner (Eds), Autonomous Driving (pp. 213-231). Berlin: Springer.

Jiangsu Institute of Urban Planning and Design (2011). The comprehensive planning of Jiangyin (2011-2030). Retrieved from http://www.jiangyin.gov.cn/doc/2012/05/10/399237.shtml

Levine, J., \& Garb, Y. (2002). Congestion pricing's conditional promise: Promotion of accessibility or mobility? Transport Policy, 9(3), 179-188.

Li, Y., Wang, H., Wang, W., Liu, S., \& Xiang, Y. (2016a). Reducing the risk of rear-end collisions with infrastructure-to-vehicle (I2V) integration of variable speed limit control and adaptive cruise control system. Traffic Injury Prevention, 17(6), 597-603.

Li, Y., Zhang, L., Peeta, S., He, X., Zheng, T., \& Li, Y. (2016b). A car-following model considering the effect of electronic throttle opening angle under connected environment. Nonlinear Dynamics, 85(4), 2115-2125.

Litman, T. (2018). Autonomous vehicle implementation predictions. Victoria, BC: Victoria Transport Policy Institute.

Meng, Q., Liu, Z., \& Wang, S. (2012). Optimal distance tolls under congestion pricing and continuously distributed value of time. Transportation Research Part E: Logistics and Transportation Review, 48(5), 937-957.

Meyer, J., Becker, H., Bösch, P. M., Axhausen, K. W. (2017). Autonomous vehicles: The next jump in accessibilities? Research in Transportation Economics, 62, 80-91.

Milakis, D., Kroesen, M., \& van Wee, B. (2018) Implications of automated vehicles for accessibility and location choices: Evidence from an expert-based experiment. Journal of Transport Geography, 68, 142-148.

Milakis, D., Snelder, M., van Arem, B., van Wee, B., \& de Almeida Correia, G. H. (2017a). Development and transport implications of automated vehicles in the Netherlands: Scenarios for 2030 and 2050. European Journal of Transport and Infrastructure Research, 17(1), 63-85.

Milakis, D., van Arem, B., \& van Wee, B. (2017b). Policy and society related implications of automated driving: A review of literature and directions for future research. Journal of Intelligent Transportation Systems, 21(4), 324-348.

Narayanan, S., Chaniotakis, E., \& Antoniou, C. (2020). Shared autonomous vehicle services: A comprehensive review. Transportation Research Part C: Emerging Technologies, 111, 255-293.

Papa, E., \& Ferreira, A. (2018). Sustainable accessibility and the implementation of automated vehicles: Identifying critical decisions. Urban Science, 2(1), 5.

Pigou, A.C. (1920). The economics of welfare. London: Transaction Publishers.

SAE International. (2016). Taxonomy and definitions for terms related to driving automation systems for on-road motor vehicles. Warrendale, PA: SAE International.

Salazar, M., Rossi, F., Schiffer, M., Onder, C. H., \& Pavone, M. (2018). On the interaction between autonomous mobility-on-demand and public transportation systems. Paper presented at the 2018 International Conference on Intelligent Transportation Systems (pp. 2262-2269), Maui, HI.

Simoni, M. D., Kockelman, K. M., Gurumurthy, K. M., \& Bischoff, J. (2019). Congestion pricing in a world of self-driving vehicles: An analysis of different strategies in alternative future scenarios. Transportation Research Part C: Emerging Technologies, 98, 167-185. 
Sun, D. J., \& Ding, X. (2019). Spatiotemporal evolution of ridesourcing markets under the new restriction policy: A case study in Shanghai. Transportation Research Part A: Policy and Practice, 130, 227-239.

Sun, D. J., Zhang, K., \& Shen, S. (2018). Analyzing spatiotemporal traffic line source emissions based on massive didi online car-hailing service data. Transportation Research Part D: Transport and Environment, 62, 699-714.

Talebpour, A., \& Mahmassani, H. S. (2016). Influence of connected and autonomous vehicles on traffic flow stability and throughput. Transportation Research Part C: Emerging Technologies, 71, 143-163.

Tian, D., Zhou, J., Wang, Y., Lu, Y., Xia, H., \& Yi, Z. (2015). A dynamic and self-adaptive network selection method for multimode communications in heterogeneous vehicular telematics. IEEE Transactions on Intelligent Transportation Systems, 16(6), 3033-3049.

Tscharaktschiew, S., \& Evangelinos, C. (2019). Pigouvian road congestion pricing under autonomous driving mode choice. Transportation Research Part C: Emerging Technologies, 101, 79-95.

Wadud, Z., MacKenzie, D., \& Leiby, P. (2016). Help or hindrance? The travel, energy and carbon impacts of highly automated vehicles. Transportation Research Part A: Policy and Practice, 86, 1-18.

Wei, B., \& Sun, D. (2018). A two-layer network dynamic congestion pricing based on macroscopic fundamental diagram. Journal of Advanced Transportation, 2018. doi.org/10.1155/2018/8616120

Yang, H., \& Huang, H. J. (1998). Principle of marginal-cost pricing: How does it work in a general road network. Transportation Research Part A: Policy and Practice, 32(1), 45-54.

Yang, H., Lu, X., Cherry, C., Liu, X., \& Li, Y. (2017). Spatial variations in active mode trip volume at intersections: A local analysis utilizing geographically weighted regression. Journal of Transport Geography, 64, 184-194.

Yang, K., Menendez, M., \& Zheng, N. (2019). Heterogeneity aware urban traffic control in a connected vehicle environment: A joint framework for congestion pricing and perimeter control. Transportation Research Part C: Emerging Technologies, 105, 439-455.

Yuan, M., Song, Y., Hong, S., \& Huang, Y. (2017). Evaluating the effects of compact growth on air quality in already-high-density cities with an integrated land use-transport-emission model: A case study of Xiamen, China. Habitat International, 69, 37-47.

Zhang, K., Sun, D., Shen, S., \& Zhu, Y. (2017). Analyzing spatiotemporal congestion pattern on urban roads based on taxi GPS data. Journal of Transport and Land Use, 10(1), 675-694.

Zhang, X., \& Yang, H. (2004). The optimal cordon-based network congestion pricing problem. Transportation Research Part B: Methodological, 38(6), 517-537.

Zhong, S., Wang, S., Jiang, Y., Yu, B., \& Zhang, W. (2015). Distinguishing the land use effects of road pricing based on the urban form attributes. Transportation Research Part A: Policy and Practice, 74, $44-58$.

Zhong, S., \& Bushell, M. (2017a). Built environment and potential job accessibility effects of road pricing: A spatial econometric perspective. Journal of Transport Geography, 60, 98-109.

Zhong, S., \& Bushell, M. (2017b). Impact of the built environment on the vehicle emission effects of road pricing policies: A simulation case study. Transportation Research Part A: Policy and Practice, 103, 235-249.

Zhong, S., Xiao, X., Bushell, M., \& Sun, H. (2017). Optimal road congestion pricing for both traffic efficiency and safety under demand uncertainty. Journal of Transportation Engineering, Part A: Systems, 143(4), 04017004. 